\title{
El miedo a los pobres
}

\section{José M. Castillo, Centro de Reflexión Teológica, San Salvador.}

\section{El miedo de los poderosos}

En los evangelios sinópticos hay ocho textos en los que se dice que las personas que ejerćáan el máximo poder, en la sociedad judía del tiempo de Jesús, tenían miedo (Mc 11, 18. 32; 12, 12; Mı 14, 5; 21 , 26. 46; Lc 20, 19; 22, 2). Es verdad que, en estos textos, algunos son paralelos, como es el caso de los que refieren al linal de la parábola de los viñadores homicidas (Mc 12, 12; Mı 21,46 ; Lc 20, 19) o también los que indican la reacción de los dirigntes ante la pregunta de Jesús sobre el origen del bautismo de Juan (Mc 11, 32; Mt 21, 26). Pero, aun teniendo esto en cuenta, el hecho de que los evangelios insistan repetidas veces en el miedo de las autoridades, es un dato a lomar en consideración, si es que queremos comprender exactamente las consecuencias que se siguieron de la enseñanza y del comportamiento de Jesús. Sobre todo si tenemos presente que, en todos los textos citados, se utiliza siempre el verbo phobéomai, asustarse, espantarse, tener miedo, derivado de phóbos, angustia, temor'.

1. W, Mundle, Temor, en L. Coenen, E. Beyreuther, H. Bietenhard, Diccionario teológico del Nuevo Testamento, Vol. IV, Salamanca. 1984, p. 246. Aqu! conviene recordar que el "miedo" (phóbos) es una de las cuatro pasiones fundamentales que había que dominar para vivir de acuerdo con la naturaleza, según los estoicos, ya desde Zenón. Crf. H. von Arnin, SVF (stoicorum Veterum Fragmenta) I, 21I; III, 378; 381; 391; 412; 444. Cfr. A. López Eire, Diógenes Laercio. Los filósofos estoicos, Barcelona, 1990, p. 183. En el griego clásico, el verbo phobéomai se usaba más para hablar del miedo a los hombres, mientras que el miedo a los dioses se expresaba con sébomai. En los evangelios es frecuente la utilización de phobéomai para hablar del temor religioso (Mt 9, 8; 10, 28; 17, 6-7; 28, 4; Mc 4, 41; 9, 6; 16, 8; Lc 1, 13.30.50; 9, 34, etc.). 
Ahora bien, a la vista de estos textos, hay que hacerse tres preguntas: ¿qué clase de personas eran las que tenian miedo?, ¿a quién tenían miedo? y ¿por qué scntían ese miedo?

\section{1. ¿Quiénes tuvieron miedo?}

En cuanto a la primera pregunta, el evangelio de Mateo dice que Herodes quería matar a Juan Bautista, pero "tuvo miedo" (ephobéthe) (14, 5). Mucho "más miedo" (nuallon ephobéthe) tuvo Poncio Pilato en cl proceso de Jesús (Jn $19,8)^{2}$. Pero en este caso, el miedo de Pilato es provocado por un cierto contacto, al menos presunto, con lo sobrenatural". Lo que hace que el miedo de Pilato fuera muy distinto del de Herodes, como indicaré al responder a la segunda pregunta. En los demás textos, antes citados, que hablan del miedo, las personas que sufrían esa experiencia fueron siempre las mismas: los miembros de la clase gobernante, es decir, los componentes del Gran Consejo o Sanedrín, que era la suprema autoridad administrativa y judicial para los judíos de aquel liempot. Ahora bien, del Sanedrín eran miembros tres grupos de personas: los "sacerdotes" jefes (la aristocracia sacerdotal), los "ancianos" (la nobleza laica) y los "escribas"." El poder de los escribas radicaba en el saber, puesto que eran los que interpretaban autoritativamente la Escritura". La importancia de los ancianos estaba en que, junto con los sacerdotes jefes, eran (según Josefo) "los primeros de la ciudad". "los jefes del pueblo", "los notables", "los poderosos", "los poderosos y los notables del pueblo"?. Por tanto, sumos sacerdoles, ancianos y escribas eran los tres grupos que acaparaban el poder en la sociedad en que vivió Jesús.

Pues bien, precisamente de estos tres grupos de personas es de los que los evangelios nos informan que, al menos en determinados momentos, sufrieron la experiencia del miedo: "sumos sacerdotes y ancianos" (Mt 21, 26. 46; Lc 20,

2. La raducción no debe ser que "tuvo (aún) más miedo", ya que el relato de la pasión según Juan no se ha dicho nada anteriormente sobre el miedo de Pilato. Por eso, de acuerdo con la gramática, la frase se puede traducir en el sentido de un superlativo absoluto: temió mucho, excesivamente. Cf. S. Légasse, El proceso de Jesús, Bilbao. 1996, pp. 474-475.

3. Cfr. S. Légasse, o. c.. p. 475. En el mismo sentido: Jn 6, 19-20; Mc 4, 41; 5, 15.

4. Un buen resumen informativo sobre la composición del Sanedrín. en J. L. Sicre. El Cuadrante, Vol. II, Estella, 1997, pp. 28I-287, con las pertinentes refrencias a los conocidos estudios de J. Jeremias y E. Schürer.

5. El partido fariseo del Sanedrín estaba compuesto íntegramente por escribas. J. Jeremias. Jerusalén en tiempos de Jesús, Madrid, 1977, p. 252.

6. J. Jeremias, o. c., p. 251.

7. Referencias en Diferreiniats porBiplia4aa "P. Florentino Idoate, S.J."

Universidad Centroamericana José Simeón Cañas 
19); "sumos sacerdotes y escribas" (Mc I1, 18; Lc 22, 2); "sumos sacerdotes, escribas y ancianos" (Mc 11, 32; 12, 12). Los sumos sacerdoles están en todos los lexios y en primer lugar. menos en Lucas 20, 19, que menciona a los escribas antes que a los sumos sacerdotes.

En cuanto a la historicidad de estos textos, el miedo de Herodes (Mt 14, 5) está atestiguado por la información que Josefo suministra sobre el fín de Juan Bautista ${ }^{x}$. El dato que aporta Marcos según el cual la expulsión de los comerciantes del templo "llegó a oídos de los sumos sacerdotes y de los escribas" y que eso les incitó a querer matar a Jesús, pero que no lo hicieron por miedo $(11,18)$, es considerado, por S. Légasse, como dudoso porque se trataría dc uno de csos "estribillos" del evangelista, como otros textos que mencionan el proyecto asesino contra Jesús (Mc 3,6;12,12;14,1-2)". Sin embargo, no todos los comentaristas piensan lo mismo. J. Gnilka indica que lo del miedo de las autoridades es una apostilla que pretende explicar por qué no actuaron inmediatamente contra Jesús ${ }^{\prime \prime}$. Por su parte, R. Pesch piensa que el dato del miedo es la primera ocasión que tienen los redactores de la pasión para poner de manifiesto el enfrentamiento de los dirigentes de Jerusalén contra Jesús, como ocurre en los textos de Marcos 12, 12 y 14, I-2"'. En cualquier caso, el final de la parábola de los vin̄adores homicidas (Mt 21, 46; Mc 12, 12; Lc 20, 19) resulta perleclamente comprensible, dada la naturaleza del relato. Por otra parte, aunque hay quienes piensan que la parábola es producto de la comunidad de Marcos, autorizados exegetas, como Jeremias, Michaelis, Hengel, Pesch, Crossan y Newell'2 opinan que se trata de una parábola de Jesús. Por último, es concorde la información de los tres sinópticos en el sentido de que las autoridades buscaban la coyuntura favorable para arrestar a Jesús, evitando un posible alboroto del pueblo, lo que según Lucas motivó el miedo en los dirigentes (22, 1-2; cfr. Mt 26, 3-5; Mc 14, I-2). Por lo demás, el relato de Juan 11, 47-53 expresa con claridad el miedo de los miembros del Sanedrín $(J n$ 11, 47) a que la popularidad de Jesús se tradujera en un atentado de los romanos contra sus poderes.

Por tanto, se puede alirmar que el conjunto de los textos citados arroja como conclusión que, efectivamente, los poderosos (Herodes y los más altos

8. Se trata de un dato fíable. como ya probó J. Klausner, Jesús de Nazaret, 1933. p. 353s. Citado por P. Bonnard, Evangelio según Mateo, Madrid, 1976, pp. 328329.

9. S. Légasse, El proceso de Jesús. La historia, p. 57. Estos "estribillos" estartan destinados a preparar al lector para la cumbre que constituye la Pasión.

10. J. Gnilka, El evangelio según san Marcos, Vol. II, Salamanca, 1986, p. 152.

11. R. Pesch, Das Markusevangelium. Vol. II. Freiburg. 1984, p. 199.

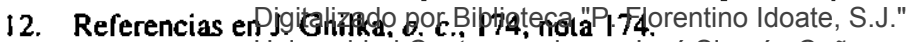


dirigentes de la religión) sufrieron la experienia del miedo con motivo de la predicación y de la conducta de Jesús, sobre todo en vísperas de la pasión, cuando el conflicto entre Jesús y las autoridades alcanzó mayor intensidad.

\section{2. ¿A quién tuvieron miedo?}

En este punto, los textos citados al principio son unánimes. Todos coinciden en una cosa: los poderosos le tenían miedo al "pueblo". Sólo en Marcos 11, 18, se dice que los sumos sacerdotes y escribas temían a Jesús. Pero el texto añade enseguida: "pues todo el pueblo estaba asombrado de su enseñanza" (Mc 11, 18c). En definitiva, por tanto, el miedo estaba motivado por el pueblo.

El problema está en determinar a quién se refieren los evangelios cuando hablan del "pueblo". Es decir, en realidad, ¿quiénes eran aquellas gentes que provocaban el miedo en los dirigentes, o sea, en los poderosos?

Cuando se trata del miedo de Herodes, el evangelio de Mateo dice que el "pueblo" al que temía el rey era el óchlos $(14,5)$. Referido ya a los dirigentes religiosos, el miedo vuelve a aparecer, sólo en Marcos, con motivo de la expulsión de los comerciantes del templo; y en ese caso, se dice que los sumos sacerdotes y los escribas le temían a Jesús, pero por causa del asombro que producía su enseñanza en el óchlos $(11,18)$. Enseguida se repite la indicación del miedo que tenían los poderosos de Israel con ocasión de la pregunta sobre la potestad (exousía) de Jesús (Mc 11, 28 par). En este caso, Mateo dice que tenían miedo al óchlos $(21,26)$, mientras que los otros dos sinópticos hablan del "pueblo" utilizando el término laós (Mc 11, 31; Lc 20, 6). Poco después aparece de nuevo el miedo al pueblo, al final de la parábola de los viñadores homicidas; y aquí, mientras Marcos y Mateo se refieren al óchlos (Mc 12, 12; Mt 21, 46), Lucas habla del laós $(20,19)$. Por último, el miedo de sumos sacerdotes y escribas se señala al narrar la traición de Judas, pero en este caso Lucas dice que a quien temían era al laós $(22,2)$. Y todavía una indicación que tiene su importancia: poco antes de comenzar el relato de la pasión, Marcos informa que los sumos sacerdotes y los escribas "andaban buscando cómo prender (a Jesús) con astucia para matarle". Y añade: "No durante la fiesta, no sea que se arme tumulto del pueblo" (óchlos) $(14,2)$.

Así, pues, cuando los evangelios hablan del miedo que los dirigentes tenían al pueblo, en cinco ocasiones lo hacen utilizando el término óchlos y en tres casos se refieren al laós. Más en concreto, en Mateo siempre aparece óchlos (14, $5 ; 21,26.46)$; en Marcos, dos veces óchlos $(11,18 ; 12,12 ; c f r .14,2)$ y una sola vez laós $(11,32)$; en Lucas, las dos veces que habla del miedo de los poderosos, dice que ese miedo era causado por el laós. Pero aquí se debe recordar que, en el vocabulario de Lucas, laós equivale a óchlos ${ }^{13}$. Como

13. Por ejemplo, Lc 7,29 y 7, 24; Lc 8,45 y 8,47 .

Digitalizado por Biblioteca "P. Florentino Idoate, S.J."

Universidad Centroamericana José Simeón Cañas 
taınbién hay textos en los que un evangelista usa laós donde otro evangelio pone óchlos's. Por eso. no me parece que sea aceptable afirmar, sin más explicaciones, que óchlos tiene un sentido "prosaico", mientras que laós tiene un sentido "teológico"'s. En realidad, esos dos términos son expresiones muy importantes de la tcología de los evangelios sinópticos. Porque son las dos palabras que nos dicen quién estuvo realmente de parte de Jesús. Y, por tanto, quién comprendió de verdad su mensaje y quién lo aceptó.

Pcro, en esta cuestión, hay matices que interesa señalar. No faltan quienes piensan que el término óchlos se ha de traducir únicamente por "multitud", "masa" o "muchedumbre". Es decir, se pone el acento en la "cantidad", no precisamente en la "clase" de personas que se acercaban a Jesús y que se agolpaban junto a él para escucharlo". Sin embargo, aquí es importante recordar que óchlos, según los diccionarios más autorizados, expresa la idea de "multitud" de gente. Pero, sin duda alguna, no se reliere sólo a la cantidad de personas, sino sobre todo a la "condición social" de esas personas. En efecto, óchlos se traduce por "vulgo" o "plebe" (Volkshaufe), en sentido despectivo", de manera que el uso más frecuente de esta palabra es el de "masa" (foule), por oposición a los jefes, con una coloración política peyoraliva ${ }^{1 \mathrm{k}}$. Más en concrelo, óchlos se entiende, en el griego clásico, no sólo como "pueblo", en contraposición a la persona singular, sino de manera más específica se refiere a la multitud del "vulgo", en cuanto distinta del aristócrata y de la clase dirigente polf́tica o cultural. En este sentido, esta palabra sirve para delīnir a la "gente anónima", la "plebe", frente a las clases superiores y a las diversas autoridades". Se trata sencillamente de la "masa privada de finalidad y dirección, la plebe sin importancia política o cultural"=n. Lo que es cierto hasta el punto de que Platón niega a la masa del pueblo incluso la capacidad para emilir un juicio ${ }^{21}$.

14. Por ejemplo, LC 19, 48 y Mc 11, I8; Lc 20, 45 y Mt 23, 1; etc.

I5. F. Bovon, Das Evangelium nach Lukas, EKK III/I, Zürich. 1989, p. 286.

16. En este sentido. por ejemplo. P. Chantraine. Dictionnaire Ethymologique de la langue grecque. París. 1968. p. 845.

17. H. Frisk, Griechisches Etymologisches Wörlerbuch, Vol. II, Heidelberg, 1973, Pp. 456-457. En el mismo sentido, H. G. Liddel-R. Scoll, A Greek-Eglish Lexikon. Vol. II. Oxford, 195I, p. 128I. También el clásico diccionario de Slephanus, Thesaurus Graecae Linguae. Vol. VI. Graz. 1954. pp. 2476-2477; A. Bailly, Dictionmaire Grec Françcais. París, 1950. p. 1433.

18. P. Chantraine, o. c., p. 845.

19. R. Meyer: TWNT V. 582, que remite a un relato militar de la época tolemáica.

20. R. Meyer, o. c.. pp. 682-683.

21. Sus palabras son tajantes: "Es ridícula la gran multitud (polys óchlos) si pretende

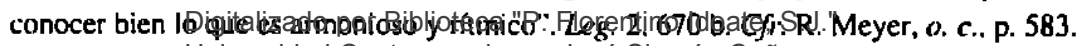

Universidad Centroamericana José Simeón Cañas 
Por todo esto se comprende que, cuando los evangelios hablan del óchlos, se refieren a la multitud (Mt 4, 18; Lc 4, 42), en la que abundaban los enfermos y los que eran tenidos por endemoniados (Mt 8, 16; Lc 4, 40-41). Es decir, gentes con "dolencias" y "enfermedades" (Mt 8, 17; cfr. Is 53,4). Se trataba de todos aquellos que "andaban maltrechos y derrengados como ovejas sin pastor" (Mt 9, 36 ; Mc 6,34). Más concretamente, eran los pobres, los que no tenían qué comer y a los que Jesús alimenta (Mc 6, 45; Mt 14, 19; Lc 9, 11; Jn 6, 2.5.22.24), de manera que "venían de lejos" y "en ayunas", con peligro de "desfallecer en el camino" (Mc 7, 2; Mt 15, 32). En definitiva, las multitudes que, según los relatos evangélicos, constituyeron "el trasfondo anónimo sobre el que se desarrolló la actividad de Jesús"'22. Teniendo siempre en cuenta que, la sociedad en que vivió Jesús, como todas las sociedades agrarias del siglo primero, estaba marcada por una profunda desigualdad ${ }^{23}$. Concretamente, el pequeño campesinado constituía la gran masa del pueblo, que frecuentemente pasaban a engrosar el estrato más bajo, el de los pobres ${ }^{24}$. Según las estimaciones más fiables, seguramente más del 90 por ciento de la población (si sumamos a los campesinos los artesanos y los despreciables) ${ }^{25}$ pertenecía al "pueblo" pobre y sencillo, el óchlos, la masa enorme de los que eran considerados por los poderosos como la "turba que no conoce la Ley y son unos malditos" (Jn 7, 48).

A estas gentes, en definitiva a los pobres, es a quienes tenían miedo los poderosos del tiempo de Jesús. Lo cual quiere decir que los pobres estimaban tanto a Jesús, y se sentían hasta tal punto identificados con él y con sus enseñanzas, que las autoridades temían atentar contra Jesús porque sabían que eso era lo mismo que atentar contra el pueblo, contra la enorme masa de los pobres. Los poderosos no tenían miedo a los "discípulos" de Jesús. Eso no se dice en ninguna parte. A quien tenían miedo los dirigentes y los notables era a los pobres.

\section{3. ¿Por qué tuvieron miedo?}

En las sociedades de nuestro tiempo, no es frecuente que las autoridades tengan miedo a los pobres. Ni los políticos, ni los hombres de las finanzas y la

22. R. Meyer: TWNT V, 586; cfr. H. Balz, en H. Balz, G. Schneider, Diccionario Exegético del Nuevo Testamento, Vol. II, Salamanca, 1998, p. 665; P. Zingg, Das Wachsen der Kirche, Freiburg (Suiza)-Göttingen, 1974, pp. 61-63.

23. Cfr. G. E. Lenski, Power and Privilege: A Theory of Social Stratification, New York, 1966, p. 210; J. D. Crossan, Jesús: vida de un campesino judio, Barcelona, 1994, p. 80.

24. J. L. Sicre, El Cuadrante, Vol. II, Estella, 1997, pp. 292-293, que cita el amplio estudio de W. Bösen, Galiläa als Lebensraum und Wirkungsfeld Jesu, Freiburg, 1985, pp. 186-187.

25. Cfr. J. L. Sicre, o. c., pp. 293-294; 296-297, con bibliografía. Digitalizado por Biblioteca "P. Florentino Idoate, S.J." Universidad Centroamericana José Simeón Cañas 
cconomía, ni los militares, ni la policía, ni los jucces, ni tampoco las autoridades religiosas parecen dar muestras de que los pobres los asusten. Puede ser que haya gohernantes que, quizá por motivos de conciencia, se sientan preocupados por el problema que representan los pobres hoy en el mundo. Pero miedo, lo que se dice miedo, no parece que los pobres estén hoy en condiciones de provocárselo a los que tienen en sus manos el poder en el mundo, ya se trate de poder político. econóınico o religioso.

En tiempos de Jesús, sin embargo, las cosas no eran lo mismo. Por tres razones que se comprenden enseguida. En primer lugar, porque en la sociedad de aquel tiempo apenas había clasc media. En Jerusalén, según los datos que aporta J. Jeremias, se podían considerar personas de clase media los pequeños comerciantes, los empleados del templo, los que se dedicaban a la industria del hospedaje (que era importante en las fiestas) y los simples sacerdotes ${ }^{26}$. Pero en la sociedad agraria de Galilea, era abismal la distancia que separaba a ricos de pobres, como ya he dicho. En cualquier caso, la estructura social de aquel tiempo estaba configurada de tal forma que la gran masa de los "satisfechos" no era la predominante. como lo es ahora en los países desarrollados. Naturalmente, desde el momento en que las gentes de condición humilde constituían la gran mayoría de la población. las autoridades se veían obligadas a tener sumo cuidado con la inmensa cantidad de personas a las que, con toda razón, se les podía considerar como el óchlos, o sea, el "pueblo" sencillo de los pobres. Y es evidente que una agilación multitudinaria de gentes "insatisfechas" podía representar un serio peligro para los gobernantes.

En segundo lugar, nunca debemos olvidar que la situación política del pueblo judío, en aquellos años, era sumamente inestable. Era un pueblo dominado políticamente por la ocupación romana. $Y$ se sabe que en la práctica el dominio de Roma representaba para la gente, según el testimonio del historiador romano Cornelio Tácito, "robar, asesinar y asaltar", Ilamando "con falso nombre imperio y paz al sembrar la desolación'" circunstancias, las autoridades religiosas judías tenían que extremar los cuidados para que no se provocase ningún lipo de tumulto popular. De ahí, un motivo añadido al miedo que los dirigentes tenían al pueblo que mayoritariamente era pobre.

Y en tercer lugar, está el hecho de que ni Herodes, en Galilea, ni el Sanedrín, en Jerusalén, tenían una policía (y menos un ejército) con medios eficientes para controlar una sublevación del pueblo, ni siquiera un tumulto popular. Cuando

26. J. Jeremias, Jerusalén en tiempos de Jesús. pp. I19-127.

27. Texto citado por J. L. Sicre, El Cuadrante, Vol. II, p. 71. Cfr. J. D. Crossan, Jesús: vida de un campesino judio, p. 77. El historiador Cornelio Tácito es un siglo posterior al tienipitalizapesưs. Biblioteca "P. Florentino Idoate, S.J."

Universidad Centroamericana José Simeón Cañas 
arrestaron a Jesús, en la noche de la pasión, los que se presentaron a prenderlo fueron sencillamente "una multitud con espadas y palos" (Mc 14, 43; Mi 26, 47) ${ }^{2 \mathrm{k}}$. El evangelio de Juan habla de "guardias" (hypêretas), proporcionados por "los sumos sacerdotes y lariseos" $(\mathrm{J} n \mathbf{1 8}, 3)$, pero en realidad, como indica $S$. Légasse, tales guardias "no marcaban una diferencia esencial con respecto a los otros evangelios"2". Se comprende, pues, que unas autoridades que carecían de una policía elicaz, para delenderse de una eventual agresión, debían tener miedo a cualquier agitación Jel pueblo que, en aquellas circunstancias, venía a ser como una agilación de los pobres.

Las tres razones que acabo de indicar están suficientemente insinuadas en los evangelios. Seguramente, el texto más clocuente, en este sentido, es uno en el que no se menciona el "miedo", pero en el que, sin duda alguna, el miedo es el verdadero molor de la decisión que toma el sanedrín. Me refiero al relato del evangelio de Juan en el que se dice que, después que Jesús le devolvió la vida a Lázaro, "los pontífices y los fariseos" (Jn 11, 47) decían: "Si lo dejamos continuar así, todos creerán en él, y vendrán los romanos y acabarán con el lugar santo y con la nación" (Jn II, 48). En consecuencia, la decisión que tomaron fue dar muerte a Jesús (Jn 11, 53). Lo primero que aquí aparece es una motivación política. El movimiento popular que suscitaría la actividad de Jesús, de dejarle continuar, sería un buen pretexto para una intervención de los romanos y la pérdida de los últimos restos de autonomía nacional. Por más que Juan le dé a todo esto una interpretación teológica, el hecho histórico parece suficientemente atestiguado". Es el miedo de unas autoridades que temen, ciertamente, a los romanos. Pero, antes que a los romanos, a quien tienen miedo es al pueblo, concretamente a que el pueblo "crea en Jesús" ( $c f r$. Jn II , 48).

El miedo (sin mencionar esa palabra) vuelve a aparecer en los tres grupos que formaban el sanedrín, sumos sacerdotes, ancianos y escibas, cuando plantean la pregunta sobre la potestad de Jesús (Lc 20,1-2). Y es miedo al "pueblo entero" (laós ápas), concretamente porque temen que la gente los apedree (katalithásai) (Lc 20,6). Como también sin mencionarlo, el miedo es lo que impulsa a los sumos sacerdotes y escribas a prender a Jesús "con astucia" (Mc 14, 1), pero no durante la fiesta, "no sea que se arme tumulto del pueblo" (Mc 14, 2).

28. AquI se utiliza óchlos, pero sin artículo, que indica simplemente "canlidad", o sea. "multitud" de personas. Serla como una "banda" o "tropa", cosa que está atestiguada por el griego clásico. S. Légasse, El proceso de Jesús. La pasión en los cuatro evangelios, Bilbao, 1996, p. 26, nota 3. Cfr. R. Meyer: TWNT V, p. 583.

29. O. c., p. 425.

30. Cfr. R. Schnackenburg, El evangelio según san Juan, Vol. II, Barcelona, 1980, p. 442. 
En definitiva, con las inevitables variantes por las circunstancias distintas de cada caso, lo que siempre aparece es el miedo que tenían "los más poderosos del pueblo", precisamente al pueblo, a los pequeños y a los pobres. Y siempre se trataba del mismo motivo: el miedo a perder el poder. Por eso, el miedo al pueblo se indica, de manera explícita (Mc 11, 32par), cuando los que detentan el poder plantean la cuestión del "poder" (exousía) con que actúa Jesús (Mc 11 , 28par). Como se vuelve a indicar expresamente al final de la parábola de los viñadores homicidas (Mc 12,12par), cuando los dirigentes se dan cuenta de que van a perder sus privilegios (el "reino", la "viña") y todo eso se les "dará a otros" (Mi 21, 43; Mc 12, 9).

\section{Los pobres le quitan la máscara al poder}

Los datos que suministran los evangelios sobre la decisión de matar a Jesús, indican claramente que tal decisión resultó complicada, incluso peligrosa, para quienes la tomaron, es decir, los miembros del sanedrín. Que resultó complicada, es algo tan patente en los relatos de la pasión, que se ha dicho con razón que el proceso religioso contra Jesús "fuc una mascarada de justicia: su fin no fue pronunciar una sentencia equitativa, sino "matar" a Jesús".3. De ahí, el desacuerdo de los testigos que intervinieron en el proceso (Mc 14, 55-59par). Que además de complicada fue también peligrosa, ya lo hemos visto: las autoridades temieron que aquello provocara un "tumulto" (Mc 14, 2) y hasta pensaron en la posibilidad de ser "apedreados" por el pueblo (Lc 20,6).

En realidad, el miedo estaba causado por algo mucho más grave. Lo que allí estaba en juego no era un conflicto pasajero, sino la pérdida del poder, como ya he dicho. Pero, es claro, en aquel tiempo y entre aquellas autoridades, ocurría lo que siempre ha ocurrido y sigue ocurriendo con todos los que disfrutan de un poder y no quieren perderlo. Como eso es algo sencillamente inconfesable, quienes se ven en semejante situación buscan "razones" y "argumentos", que enmascaren sus verdaderas intenciones. $Y$ entonces se apela a la defensa de la patria, al bien de la religión o incluso a la voluntad de Dios. De donde resulta que la patria, la religión y, si es necesario, Dios y su santísima voluntad son las grandes máscaras que ocultan el verdadero rostro del poder, el rostro deforme y feo de la pasión por el poder.

Eso justamente es lo que, a juicio del evangelio de Juan, ocurrió cuando sentenciaron a Jesús. Los sumos sacerdotes y los fariseos, es decir, los dos grupos que, para el cuarto evangelio, representan a las autoridades judías sobre las que carga la responsabilidad de la muerte de Jesús ${ }^{32}$, convocan una reunión

31. S. Légasse, El proceso de Jesús. La pasión en los cuatro evangelios, 44.

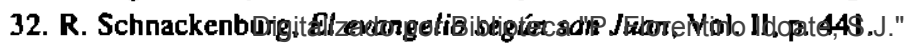

Universidad Centroamericana José Simeón Cañas 
olicial del sanedrín (Jn II. 47) y presentan la gravedad de la situación. Ahora bien, tal como ellos plantean el problema, el peligro no está en que, si todo el pueblo cree en Jesús (Jn II, 48 a), no va a seguir creyendo en ellos y, por tanto, van a perder el poder que ticnen sobre la gente. Lo que dicen es que, si el pucblo entero se pone a creer en Jesús, entonces, lo que va a ocurrir es que los romanos les van a quitar" el "lemplo" los "hombres del poder" no hablan de la pérdida del poder, que es donde estaba el verdadero problema para ellos. De lo que hablan aquellos hombres es de la pérdida de la religión y de la patria, los dos argumentos más serios y más nobles que un buen creyente y un buen ciudadano puede invocar. Pero, en rcalidad, sabemos que la "religión" y la "patria" son, con demasiada frecuencia, las dos grandes y sublimes máscaras que se ponen tantos ambiciosos de poder que, en nombre de Dios y en nombre de la nación, lo que de verdad prelenden es intentar saciar su insaciable pasión por imponerse, dominar y someter a cuantos caigan al alcance de sus inconfesables pretensiones.

Ahora bien, si algo quedó claro en toda aquella situación, es que el pueblo pobre y sencillo lue quien le quitó la ináscara al poder, exactamente a las ambiciones de poder de los dirigentes religiosos. El miedo de aquellos dirigentes a la reacción del pueblo desenmascaró sus verdaderas intenciones. Quizá lo más elocuente que aparece en los evangelios y en el libro de los Hechos, por lo que se refiere a nuestro asunto, es que los sumos sacerdotes, los ancianos y los escribas nunca aparecen como hombres piadosos y preocupados por agradar a Dios. Tampoco se dice jamás de ellos que su preocupación fuera ayudar al pueblo o estar cerca de los pobres. Todo lo contrario. Desde el primer momento en que, en los evangelios, aparecen juntos estos tres grupos de hombres, es para presentarlos como agentes de sufrimiento y de muerte. Asf, desde el primer anuncio de la pasión (Mc 8, 31; Mt 16, 21; Lc 9, 22) hasta que consuman la sentencia de muerte contra Jesús (Mc 14, 53; Mt 26, 57; Lc 22, 66). Pues bien, en todo este penoso proceso, sólo el pueblo y el miedo al pueblo es lo que pone en evidencia lo que realmente les preocupaba y les interesaba a aquellos hombres. Su único interés y su verdadera preocupación fue evitar lo que les

33. Aroûsin, de aíro, literalmente "quilar". De ahí que se puede traducir por "destruir", ya que tal es el sentido de lo que quieren expresar.

34. El texto dice tópos, el "lugar". Pero difícilmente se puede entender la capital. Se refiere claramente al templo (cfr. Jn 4, 20; "lugar santo" en MI 24, 15; Hech 6, 13; 21. 28. Cfr. "Lugar (templo) y pueblo" es una expresión acuñada desde la época de los Macabeos (cfr. 2Mac 1, 29; 5, 19). Para el sentido de tépos, H. Koster: TWNT VIII, pp. 204-205. Cfr. R. Schnackenburg, El evangelio según san Juan. Vol. II, p. 442.

35. éthnos designa a la nación judia en Lucas y Juan: $L c 7,5 ; 23,2$; Hech 10,$22 ; 24$, 2.10.17; 26, 4; 28, 19; Jn 11. 48.51.52; 18, 35. Cfr. K. L. Schmidt: TWNT II, p. 366. 
pudicra crear problemas a cllos. Y naturalmente, ellos sabían muy bien que los problemas sólo podían venir de la sintonía y de la solidaridad profunda que el pueblo tenía y vivía con la persona y la enseñanza de Jesús. En este sentido, es de notar que a los dirigentes religiosos no les preocupa la posible reacción de los "discípulos" de Jesús ni, por tanto, una hipotética protesta de quienes, a primera vista, eran los más cercanos al inquietante proleta que les causaba tanlos problemas. A las autoridades religiosas no les da miedo alguno lo que puedan hacer los "discípulos". Lo que verdaderamente les Ja miedo es lo que puedan hacer los "pobres".

\section{El problema de fondo}

La pregunta que aquí a cualquiera se le ocurre es enteramente lógica: ¿por qué son los pobres, es decir, los más débiles, los que causan el mayor miedo a los dirigentes, es decir, a los más fuertes?

Ante esta cuestión, parece que lo razonable se reduce a decir que, en aquella sociedad, los pobres eran legión. Y, es claro, una "legión", aunque sea de pobres, es una cosa que da miedo. Sobre todo, si los que se sienten amenazados no disponen de los medios suficientes (un ejército, una policía) para defenderse eficazmente. Eso, sin duda, es lo que les pasaba a los dirigentes judíos en tiempo de Jesús. Porque a ese motivo, ni más ni menos, se refieren los evangelios cuando dicen que los mandalarios del Sanedrín tenían miedo de que "el pueblo entero los apedreara" (Lc 20,6) o sencillamente de que "se armara un tumulto" (Mc 14, 2), como más tarde los "magistrados" temen "ser apedreados" por el pueblo (Hech 5, 26). En cualquier caso, el miedo de las autoridades judías a un altercado público resulta comprensible, si tenemos en cuenta que, en semejantes desórdenes, la intervención de la policía romana podía ser implacable, hasta el punto de poner en serio peligro el ya limitado poder que Roma permitía a los dirigentes judíos. Esto es lo que, como ya he dicho, motivó al Sanedrín para tomar la decisión de matar a Jesús (Jn 11, 47-53).

Todo esto es cierto. Y tuvo que influir en el miedo que ciertamente sintieron los poderosos de Israel ante la masa de los pobres de aquel pueblo. Pero si nos quedamos en esto, no tocamos el fondo del problema que en realidad allí se planteó. Porque la razón última y determinante del miedo a los pobres no estaba en el peligro de un posible alboroto popular. El miedo profundo o, si se prefiere, el miedo de fondo que los pobres provocaron en los más ilustrados y más autoritarios representantes del judaísmo está explicado en los textos evangélicos por dos motivos: porque el pueblo estaba persuadido de que Juan Bautista (Mi 14, 5; 21, 26; Mc 11, 32; Lc 20,6) y Jesús (Mt 21, 46) eran profetas; y porque el pueblo estaba impresionado y, por tanto, se identificaba con la enseñanza de Jesús (Mc 11, 18; 12, 12; Lc 20, 19). Ahora bien, ¿qué vienen a decir estos dos motivos? 
En cuanto al primer motivo (el pueblo consideraba a Jesús y a Juan Bautista como profetas), interesa caer en la cuenta de la estima profunda que la gente sentía, en aquel tiempo, por la figura, la misión y la personalidad de un "profeta". Que el pueblo estaba persuadido de que Juan Bautista ${ }^{\text {Wh }}$ y Jesús ${ }^{37}$ eran proletas, es cosa bien atestiguada en los evangelios. Por otra parte, la gente sentía lal admiración por la ligura de un proleta, que cuando Jesús se pone a ponderar la grandeza de Juan Bautisla, lo más que puede decir de él es que era no sólo profeta, sino incluso más que un profeta (MI II, 9; Lc 7, 26) ${ }^{\text {?k }}$. Parece, por tanto, que el modelo y el ideal del "profeta", como punto de referencia, era lo más que se podía aducir ante la opinión pública para enaltecer la figura de una persona. Es lo mismo que ocurre cuando Jesús devolvió la vida al hijo de la viuda de Naím. El clamor del pueblo (óchlos) ailí presente (Lc 7,11 ) es que "un gran profeta se ha levantado en medio de nosotros y Dios ha visitado a su pueblo" (Lc 7, 16). El elogio es de tal categoría que la presencia de un profeta se asocia a la presencia de Dios entre el pueblo. Más aún, cuando Jesús pregunta lo que la gente piensa de él, lo más que pueden decir sus discípulos es que la opinión popular considera a Jesús como un profela similar a los que existieron en tiempos lejanos (Mc 8, 28par)". Esto quiere decir que el "profela" cra, para aquellas gentes, "una intervención decisiva de Dios para el juicio y la salvación de los hombres" "il. Igualmente, en el evangelio de Juan, la admiración de la samaritana se traduce en decirle a Jesús: "veo que eres un profeta" (Jn 4, 19). Lo mismo que el ciego de nacimiento: lo más que puede decir de Jesús es que era un profeta $(\mathrm{Jn} 9,17)$.

Pero hay un aspecto aquí que conviene destacar. Quien sentía admiración por los profetas era el "pueblo". Por eso, como ya he dicho, los poderosos tuvieron miedo de atentar contra Jesús. En este punto concreto, se repilió la historia de liempos antiguos, los tiempos de los profetas: frente al apoyo popular que tuvieron aquellos hombres enviados de Dios ${ }^{41}$, el enlrentamiento con los poderosos, especialmente reyes y sacerdotes, es un tema bien estudiado, especialmente por lo que se reliere a las relaciones entre los profetas y los

36. Mi 11, 9; 14. 5; 21. 26; Mc 11, 32; LC I, 76; 7. 26; 20.6.

37. Mt 13. 57; 21, 11.46;26. 68; Mc 6, 4.15; 14, 65; Lc 4, 24; 7, 16.39; 13, 33; 22, 64; 24. 19; Jn 4, 19.44; 7. 52; 9. 17.

38. Juan era "más que un profeta" en cuanto que era el precursor del Mesías. Mateo y Lucas. casi con las mismas palabras, citan mezclándolos a Mal 3, 1 y Ex 23, 30 (cfr. además Is 40, 3; Mc I, 2; Jn 3, 28). P. Bonnard. Evangelio según san Mateo, Madrid 1976, p. 251.

39. J. Gnilka, El evangelio según san Marcos. Vol. II, p. 14.

40. P. Bonnard, Evangelio según san Mareo, pp. 363-364.

41. Ha analizado este apoyo popular, J. L. Sicre, Profetismo en Israel. Estella, I992, pp. 14I-142. Digitalizado por Biblioteca "P. Florentino Idoate, S.J." 
sacerdotes $^{42}$. Por eso, en los evangelios se repite de diversas maneras el conflicto de los dirigentes judíos con los profetas. Los que merecen el elogio de Jesús en las bienaventuranzas, los pobres, los que tienen hambre, los que lloran, los aborrecidos y ultrajados (Lc 6, 20-22; cfr. Mi 5, 3-12), esas gentes precisamente son los que van a correr la misma suerte que los profetas antiguos, perseguidos por los poderosos de tiempos pasados (Lc 6, 23; ML 5, 12). Y en la diatriba de Jesús contra escribas y fariseos, tal como es presentada por el capítulo 23 de Mateo, por más que se trate de un texto condicionado por la situación de una comunidad en abierta contradicción con los jefes del judaísmo ${ }^{43}$, es indudable que se reproduce el conflicto que siempre existió entre los poderosos de Israel y los profetas (ML 23, 29.30.31.35. 37; Lc 11, 47.49.50.51; 13, 34).

Ahora bien, lo determinante aquí está en recordar por qué el "pueblo" se identificó con los profelas, mientras que los "poderosos" los persiguieron y los malaron. Lo más sencillo y lo más claro que se puede decir sobre este asunto es que los profetas de Israel, siguiendo una preocupación que fue constante entre los pueblos del Antiguo Oriente Próximo, trasmitieron un mensaje en el que siempre fue una cuestión capital la lucha por la justicia, la denuncia de los problemas sociales y el esfuerzo por una sociedad más justa ${ }^{44}$. No es éste ni el sitio ni el momento de recordar la abundante documentación bíblica que existe sobre este punto. Baste recordar lo que acertadamente indica J. L. Sicre, refiriéndose al mensaje de Amós: "los más débiles desde el punto de vista social y econ6mico son maltratados, incluso vendidos como esclavos, por parte de personas sin escrúpulos, que a sus injuslicias añaden el descaro de cometerlas incluso en el templo, "junto a cualquier altar" ( $c f r$. Am 2, 6-8 $)^{4 .}$. Pues bien, estas cosas, de una manera o de otra, eran sabidas por el pueblo sencillo, la gente que se apiñana para oír a Jesús. Y es claro, si aquellas gentes pensaban que Jesús era un profeta, si lo aceptaban y lo admiraban como tal, eso quiere decir inequivocamente que los pobres veían en Jesús el defensor de sus derechos atropellados, mientras que los poderosos veían en aquel nuevo profeta el

42. Cfr. J. L. Sicre, o. c., pp. 142-143, con bibliografía en la notal9.

43. Como es sabido el evangelio de Mateo ha sido considerado como signo del antijudarsmo que se dio ya en el primitivo cristianismo. $Y$, sin duda, el ejemplo más claro de esıa tendencia se advierte en la redacción del capítulo 23 de este evangelio. Cfr. M. Gielen, Der Koflikt Jesu mit den religiösen und politischen Autoritäten seines Volkes im Spiegel der mathäieischen Jesusgeschichte. Bodenhcim 1998, $467-$ 473; H. J. Becker, Auf der Kathedra des Mose. Rabbinisch-theologisches Denken und antirabbinische Polemik in Mi 23. I-12, Berlin 1990.

44. Cfr. J. L. Sicre, Profetismo en /srael, p. 387, que remite a su estudio fundamental: "Con los pobres de la tierra". La justicia social en los profelas de lsrael, Madrid. 1985, con bibliografía en pp. 465-477.

45. J. L. Sicre, PrAjeitalizaden PSrckiplipt999."P. Florentino Idoate, S.J."

Universidad Centroamericana José Simeón Cañas 
incómodo, el ideseable portavoz que clamaba contra todos los que, de una forma o de otra, maltrataban al pueblo indefenso y se aprovechaban de él. Naturalmente, eso tenía que motivar el miedo que, según los textos evangélicos, los dirigentes le tenían al pueblo, que estaba de acuerdo con lo que Jesús decía y hacía.

Pero el miedo a los pobres, que admiraban a Jesús como profela, tenía una raíz más profunda. Porque. en última instancia, lo que allí estaba en juego era el problema de Dios. En efecto, lo primero que caracteriza al Dios de los profetas es que exige "derecho" y "justicia". Derecho, que equivale al recto ordenamiento de la sociedad; y justicia, que hace posible vivir a londo el Jerecho ${ }^{46}$. Con estos términos se expresa, a veces, lo que Dios espera del pueblo (Am 5, 24; Is 5, 7), de cada israelita (Ezequiel), como presupuesto humano para que irrumpa la salvación (Is 56,$1 ; c f r .59,9.14)^{47}$. El Dios de los profelas exige además la misericordia (Os 4, 1; Miq 7, 20). Y pide la práclica de la justicia ante los tribunales (ls 10,$2 ; \operatorname{Jer} 7,5 ; 21,12 ;$ Am 5,15 ), lo que a veces adquiere el sentido de defensa de la "causa de los pobres" (Jer 5, 28). Es el recto orden que se debe buscar (Is 1, 17), del que son especialmente responsables las autoridades (Miq $3,1.9)^{4 k}$. Si a todo esto unimos que los profetas presentaban a un Dios que mandaba denunciar a los responsables de la injusticia, no sólo al rey, sino también a las autoridades religiosas, empezando por los sacerdotes, a los que Oseas acusa de rechazar el conocimienlo de Dios $(4,4)$ y de asesinar $(6$, 9), mientras que Miqueas denuncia su codicia $(3,1$ I) y Jeremías pone de manifiesto su colaboración con la injusticia $(8,4-9,25)^{44}$, si tenemos en cuenta todo esto, se comprende perfectamente que los dirigentes religiosos que aparecen en los evangelios, al darse cuenta de que el pueblo pensaba que Jesús era un profeta, debían de tenerle miedo al pueblo, eso por supuesto. Pero si se piensa a fondo lo que allí ocurrió, se comprende que la razón última del miedo (si realmente estaba motivado porque la gente tenía a Juan Bautista y a Jesús por profelas) tenía una raíz más profunda. No era simplemente miedo a revueltas populares o a con Пictos con las autoridades romanas. Además de eso y más allá de todo eso, era miedo al Dios del pueblo, que era el Dios de los proletas. Porque ese Dios, no sólo era distinto del Dios que "legitimaba" a los dirigentes, sino que sobre todo decía que el Dios de aquellos dirigentes era la

46. Esta bina: derecho - justicia aparece en los siguientes textos proféticos: Am 5, 7 . 24; 6, 12; Is 5,7 (cfr. 1,$27 ; 9,6 ; 28.17 ; 32,16 ; 33,5$ ); Jer 22, 3.15; 23, 5; 33, 15; Ez 18. 5.19.21.27; 33, 14.16.19; 45. 9; Is 56, 1; 59. 9.14. Cfr. J. L. Sicre, “Con los pobres de la tierra". La justicia social en los profelas de Israel. Madrid, 1984, p. 441.

47. J. L. Sicre. I.c.

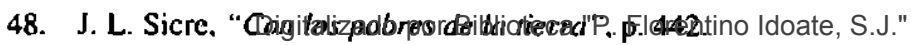

Universidad Centroamericana José Simeón Cañas 
gran mentira y la fuente de todas las mentiras y agresiones que sacerdotes, ancianos y escribas cometían contra el pueblo.

En último lérmino, lo que aquí se planlea es el problema de la idolatría y, más en concreto, la actualísima cuestión de la manipulación de Dios ${ }^{50}$. Como muy bien dijo G. von Rad, "precisamente el hombre piadoso es el que corre más peligro de configurar a Dios a su imagen o según otra imagen"si. Ahora bien, los profetas indican (entre otras) dos formas de manipular a Dios que, sin duda alguna, se daban con enorme fuerza y persistencia entre las autoridades judías que rechazaron y condenaron a Jesús. Se trata de la idolatría del templo, tan duramente condenada por Jeremías $(7,1-15$; c. 26) y la idolatŕa del día del Señor a la que se enfrenta Amós $(8,9-10)^{52}$. Pero sabemos que precisamente por expulsar a los comeciantes del templo y por no observar la ley religiosa del sábado", aquellos dirigentes encontraron argumentos "razonables", incluso de valor "divino", para enfrentarse a Jesús y hasta condenarlo a muerte "en nombre del Dios vivo" (Mt 26, 63).

El problema de fondo cuando se trata del espinoso asunto del miedo a los pobres, en tiempo de los profetas antiguos, en tiempo de Jesús, y en nuestro tiempo, es Dios. Y la prueba más clara de que ese miedo tiene su razón de ser, en último término, en la imagen que cada uno tiene de Dios, está en el segundo motivo que indican los textos evangélicos cuando hablan del miedo de los dirigentes del Sanedrín. Se trata de la referencia al miedo, en la conclusión de la parábola de los viñadores homicidas (Mc 12, 12; Mt 21, 46; Lc 20, 19). No se trata de explicar aqui la parábola ${ }^{54}$. Lo que interesa es caer en la cuenta de que los poderosos de Israel vieron, en aquella historia, que el Dios que presentaba Jesús los descalificaba, hasta el punto de considerarlos como asesinos. Pero no sólo eso. Además, Jesús les vino a decir que Dios los expulsaba y, por tanto, les quitaba toda su autoridad y todo su poder. $Y$ para colmo de males, enseguida comprendieron que el pueblo estaba de parte de lo que decía Jesús y, por tanto, en contra del Dios que ellos presentaban y al que decían que representaban.

49. J. L. Sicre, "Con los pobres de la tierra", p. 449.

50. Para este punto, cfr. las acertadas indicaciones de J. L. Sicre, Profetismo en Israel, pp. 381-385.

51. Die Wirklichkeit Gottes, en Gottes Wirken in Israel. Vorträge zum Alten Testament, Neukirchen 1974, 148. Citado por J. L. Sicre, o. c., p. 281, nota 17.

52. Cfr. J. L. Sicre, Profetismo en Israel, pp. 384-385.

53. Téngase en cuenta que el sábado, según parece, tenía ya un sentido cultual y festivo antes de Amós. Cfr. J. L. Sicre. "Con los pobres de la tierra", p. 138.

54. Amplia bibliogralfa sobre esta parábola. en J. Gnilka. El evangelio según san Marcos, Vol. Digpalli65jo por Biblioteca "P. Florentino Idoate, S.J." 
Por otra parte, si todo eso se piensa detenidamente, es lácil entender que el problema de fondo sea Dios. Porque cuando lo que está en juego es el poder "religioso", lo que en delinitiva se pone en cuestión es el origen de ese poder, que no es otro que Dios. En este mundo, Indo poder necesita ser "legitimado", para que pucda ser aceptado por aquellos que se le someten. Este principio, que de alguna manera vale para cualquier poder, es absolutamente indispensable cuando se trata del poder "religioso". Porquc, en este caso, se trata de un poder que existe como tal poder, en la inedida y sólo en la medida, en que es aceplado libremente por aquelios que lo aceptan libremente y con esa libertad se someten a él. Nunca conviene olvidar que el poder religioso se basa en las convicciones religiosas de los licles que lo aceptan. Pero sabemos que las convicciones religiosas son siempre convicciones libres. De ahí que según sea la imagen de Dios que cada cual tiene en su cabeza, asi sera la obediencia religiosa que cada uno pone en práctica.

Ahora bien, Jesús dijo que el conocimiento del verdadero Dios se oculta a los "sabios y entendidos" y se maniliesta a los "sencillos" (nepioi), los que nada lienen que decir en este mundo, los pobres, los últimos de la vida a los que nadie escucha (MI 11, 25; Lc 10, 21). Lógicamente, el Dios de los sabios y cntendidos es el imaginario religioso que "Icgitima" los derechos de los poderosos. Mientras que, por el contrario, el Dios de los nepioi, los que peor lo pasan en este mundo, lógicamente tiene que desautorizar a los causantes de tanto sufrimiento y de tanla humillación como hay en csta vida. Lo que es tanto como decir que, en úllimo término, a quien desautoriza el Dios de los pobres es al Dios que se imaginan los poderosos, es decir, el Dios que les conviene a ese lipo de personas. Eso, exactamente eso. es lo que causa, no ya miedo, sino pavor, a todos los que, en nombre de Dios, han ido y van por la vida sometiendo, dominando y agrediendo a tantos seres humanos indefensos. El miedo a los pobres es, en uiltinı término, miedo al Dios que "legitima" a todos los responsables de que en este mundo hay a lanto sufrimiento y tanto exterminio.

\section{Los disfraces del miedo}

Nunca en la Iglesia se ha hablado tanto de los pobres como en los últimos treinta años, poco más o menos desde la conferenia de Medellín (1968) hasta este final de siglo. Pero también es cierto que nunca en la Iglesia se ha tenido tanto miedo a los pobres como en los últimos treinta años. ¿Por qué ha ocurrido esto? ¿Qué ha pasado y qué está pasando en la Iglesia?

Tener miedo es una cosa de alguna manera humillante, incluso vergonzosa. Sobre todo cuando el miedo se tiene a algo o a alguien que no tendría por qué causar miedo, sino todo lo contrario: compasión, cariño, ternura... Es claro que,

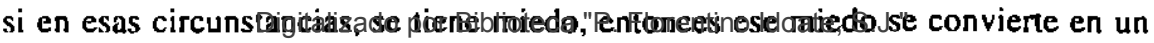


sentimiento inconfesable. Y la salida "normal", en esas condiciones, es buscarle disfraces al micdo. Para que aparezca como olra cosa lo que en realidad es miedo y, por tanto, no se puede presentar como tal. Esto exactamente es lo que ocurre con el miedo a los pobres, concretamente en la Iglesia, donde se habla con Ianta frecuencia precisamente de los pobres, afirmando que son los preleridos de Jesús y los que dcben alraer (más que nadie) nuestro interés y nuestro amor. Pero, es claro, si se dice todo eso de los pobres, ¿cómo se va a reconocer públicamente que se les tiene miedo? La salida, aquí también, es buscarle al miedo los disfraces más apropiados, los que mejor encajan con semejante situación, para conseguir dos cosas: por una parte, que la gente siga pensando que el interés por los pobres es sincero; por otra parte, que los pobres no nos compliquen demasiado la vida.

Sería una falsedad maniliesta y además una injusticia alirmar o simplemente sugerir que la Iglesia en pleno les tiene miedo a los pobres. De sobra sabemos que en la Iglesia hay cantidades incontables de creyentes auténticos que han dado y están dando lo mejor de sí mismos, con una generosidad increíble, por aliviar el sufrimiento de los más necesilados y el empeño por sacarlos de su situación desesperada. Es más, en los últimos treinta años, la preocupación por la solidaridad ha sido creciente en grandes sectores de la población mundial. Y de ese sentimiento, como no podía ser de otra manera, han participado tantos miembros de la Iglesia, que han llegado incluso a dar su vida por esta causa. Esto explica, sin duda alguna, que, en este linal de siglo, se hable tanto de los pobres y se escriba tantísimo sobre este tema. Y nadie duda que, en este enorme nujo de preocupación por la solidaridad, han jugado un papel determinante corrientes de pensamiento como la teología de la liberación o los grandes hechos eclesiales de décadas pasadas, como por ejemplo el despertar de los laicos o, más en concreto, el amplio movimiento de las comunidades eclesiales de base.

Pero si se ha hablado tanto de los pobres y tanta preocupación ha habido por ellos, eso mismo es lo que ha venido a poner en evidencia hasta qué punto los pobres resultan peligrosos y son vistos como una auténtica amenaza, para ciertas personas, determinados grupos o instituciones concretas. No hay que esforzarse demasiado para darse cuenta de que esto ha sido y sigue siendo así. Incluso en el caso de personas e instituciones que dedican documentos y libros enteros al tema de la solidaridad y del amor a los necesitados. La prueba más clara, en este sentido, es lo que ha ocurrido con la teología de la liberación y con las comunidades eclesiales de base. Que esa forma de hacer teología y de organizar la Iglesia han tenido una fuerza considerable en las últimas décadas, es cosa que sabe todo el mundo. Pero tan cierto como eso, es que, tanto la teología de la liberación como las comunidades de base, han encontrado una resistencia prácticamente insuperable en determinados sectores de la misma Iglesia.

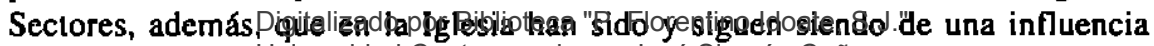
Universidad Centroamericana José Simeón Cañas 
decisiva. Y sabemos que, a estas alturas, los más cualificados representantes de tales sectores eclesiales cantan victoria. Porque, según piensan, han conseguido su objelivo. Un objetivo nunca conlesado abierlamente y con sinceridad. Pcro un objelivo que cada día resulta más evidente: neutralizar y' hasta anular el peligro que representan los pobres.

El fondo de la cuestión está en lo siguiente. Los pobres no han sido nunca peligro para nadie mientras han sido simplemente y solamente objeto de las preocupaciones y del interés que brotan del amor hacia ellos. Los pobres han empezado a ser vistos como un peligro y una amenaza, para muchos cristianos y para la institución eclesiástica misma, desde el momento en que han pretendido ser sujero de pensamiento y de decisión en la lglesia.

Me explico. Cuando los pobres no pasan de ser "objeto" de los desvelos y del amor caritativo hacia cllos, la relación con el pueblo, con los indigentes y con los ignorantes se reduce a la ajuda que se les presta. $Y$ sabemos que la "ayuda" se basa en una relación asimélrica. Porque el que ayuda está siempre por encima del que es ayudado. Lo cual quiere decir que el "ayudado" depende siempre del que "ayuda". Por lo tanto, el que ayuda es el que "sabe" en qué hay que ayudar y hasta dónde tiene que llegar la ayuda. Adernás, el que ayuda es el que "decide" en qué liene que consistir la ayuda. No creo que sea una exageración decir que, por lo general, los pobres fueron casi siempre "objeto" de interés, de preocupación y de amor en la Iglesia. Un interés, una preocupación y un amor que, normalmente, se tradujeron en "ayudarles" todo lo que se pudo. En eso la Iglesia ha sido cjemplar. Pero, fuera de contadas excepciones, la ejemplaridad de la Iglesia se quedó en eso.

El problema, para la Iglesia, se ha presentado cuando los pobres no se han resignado a quedarse para siempre en inero "objeto" del amor y la ayuda que la institución eclesiástica les puede proporcionar, sino que han pretendido ser "sujeto" que, como tal, es capaz de "pensar" y expresar su pensamiento; y además es sujeto responsable que puede "decidir" en los numerosos asuntos que le conciernen, en la sociedad y en la vida de la Iglesia. Cuando los pobres han visto las cosas de esa manera, entonces es cuando muchas personas, grupos e instituciones, en la Iglesia, se han preocupado seriamente, han sentido no sé qué extraño nerviosismo $y$, en definitiva, han pasado por la dura experiencia del miedo.

¿Por qué el miedo? La cosa resulta comprensible. Una Iglesia "pensada" desde la situación, las condiciones de vida y el destino amargo de los pobres de este mundo, sería (con toda seguridad) una Iglesia muy distinta de la que tenemos. No distinta en su estructura profunda, porque los pobres no tienen inconveniente alguno en que en la Iglesia haya obispos que realizan en el liempo la sucesión apostólica. Pero sí distinta, muy distinta, en su organización,

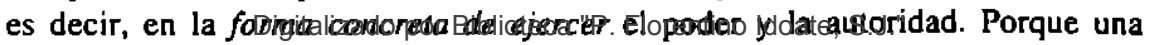
Universidad Centroamericana José Simeón Cañas 
Iglesia pensada desde los pobres, se relacionaría de manera muy diferente con los poderes de este mundo, con los gobiernos de cada país, con las instituciones económicas que deciden cómo tiene que luncionar el mercado a nivel mundial, con los grandes organismos que legislan sobre los derechos humanos y con los tribunales de justicia que, con frecuencia, dejan en libertad a los criminales y ladrones más grandes del mundo, mientras melen en las cárceles a los que roban gallinas o dan escándalos porque se emborrachan para olvidar sus penas. Además -y esto es lo más importante-. una Iglesia pensada desde los pobres, sería muy distinta, no sólo en sus relaciones "hacia fuera", sino más que nada "dentro de ella misma". Porque sería una Iglesia en la que el centro de las preocupaciones no estaría en mantener intaclo el poder, en defender a toda costa la auloridad doctrinal y en imponer sus normas, sino que el centro y la clave de todas las preocupaciones c intereses scría delender a los más débiles, no sólo publicando encíclicas o pronunciando discursos de buenas intenciones. sino sobre todo denunciando proféticamente a quienes atropellan los derechos humanos y poniéndose siempre de parte de los últimos de este mundo. Más aún. sería una Iglesia que, por ejemplo. a la hora de nombrar un obispo, no investigaría si el presunto candidato se lleva bien con el gobierno del país, sino que lo primero que sc tendría en cuenta es si el candidato a obispo tiene amigos entre los pobres, si convive con cllos. si su lonma de pensar y de vivir se parece a la forma de pensar y de vivir de los pobres.

Naturalmente, una Iglesia que, en delinitiva, no hiciera lo que les conviene a los poderosos de este mundo, sino lo que necesitan los pobres de la tierra, sería una Iglesia que se complicaría mucho la vida y tendría muchos problemas. Y eso da miedo, mucho miedo. Pero aquí es determinante caer en la cuenta de que la raíz. última de todos los miedos no está en nada de lo que acabo de decir. La cuestión de fondo, en todo esic asunto, está en que el Dios en el que creen los pobres no es como el Dios que "legitima" a los poderes que se imponen en este mundo, incluyendo a los poderes religiosos que, en nombre de Dios, oprimen a mucha gente y marginan a los que les resultan incómodos. Ahí está la motivación inconsciente de donde brotan todos los miedos, sobre todo el miedo a los pobres. Jesús dijo que los "sabios y entendidos" no conocen al Dios verdadero. Y dijo también que a ese Dios sólo lo conocen los que no representan nada en este mundo (cfr. Mt II, 25 par). Si efectivamente esto es así y, por tanto, si efectivamente Jesús liene razón, el Dios en el que (quizá sin saberlo) creen los pobres, desmonta todos los montajes y tinglados que, por sacrosantos que sean, terminan apoyando a quienes son responsables de que en este mundo haya tanto sufrimiento $y$, concretamente, tantos pobres.

La conclusión es clara: los "hombres de Iglesia" llevamos dentro, quizá sin saberlo y sin darnos cuenta de ello, motivos muy serios para tener miedo a los pobres. Por eso, tenemos miedo a darles. La palabra Y Y más ,miedo aún a que Universidad Centroamericana José Simeón Cañas 
sean ellos los que decidan en los asuntos que a nosotros nos parecen importantes.

Lo que pasa es que reconocer y confesar que llevamos dentro ese miedo es algo tan contradictorio con lo que decimos que es la razón de nuestra vida, la fe en Jesús y en su evangelio, que no nos queda más remedio que buscar disfraces para el miedo. Se trata, entonces. no sólo de "maquillar" el miedo, para que aparezca más presentable. De lo que en realidad se trata, y lo que inconscientemente se busca, es presentar cl miedo como si no fucra tal. $\mathrm{O}$ sca, como si fuera otra cosa. Y lo peor de eslc asunto es que, con bastente frecuencia, dis[razamos el miedo, no sólo ante los demás, sino también ante nosotros mismos. Porque incluso cada cual llega a convencerse de que dice lo que dice, se calla lo que se calla y hace las cosas que hace, no por miedo (a nada, ni a nadie), sino por amor, por prudencia. por discreción, por el buen equilibrio que ha de tener toda persona digna, etc., etc. Y entonces, cuando ocurre eso, superar el miedo es práclicamente imposible. Porque el que se encuentra en semejante situación busca y encuentra docenas de argumentos, todos ellos sumamente "razonables", para seguir diciendo que aclúa por amor (o por lo que sea), pero jamás por miedo.

Sin duda alguna, la historia de la teología de la liberación, en los últimos treinta años, es la prueba más clara de lo que vengo diciendo. Que esta teología ha buscado, desde el principio, no sólo escuchar a los pobrcs, sino además darles la palabra y conseguir que digan lo que piensan, quieren y esperan, es cosa que los más cualificados representantes de esta forma de hacer teología no sc han cansado de repetir, con toda clase de argumentos, desde los más teóricos hasta los hechos más concretos, sacados de la vida de miles de grupos y comunidades de creyentes por todo el mundo, especialmente en América Latina. Pero el hecho es que, por más que estas cosas se han dicho por quien podía decirlas, y por más que estas cosas se han podido comprobar por quien tenfa a su alcance comprobarlas, la pura verdad es que en la Iglesia ha habido y sigue habiendo mucha gente, y sobre todo personas constituídas en altas instancias de autoridad, que no se han creído nada de esto. Al contrario, en la teología de la liberación no se ha escuchado la voz de los pobres, sino la ideología, manipulada y manipuladora, de unos teólogos que no eran sino portavoces del marxismo y, por tanto, agitadores sociales. Es verdad que han pasado los años y, con el paso del tiempo, el comunismo se vino abajo y ya casi nadie le hace caso al marxismo. Pero la oposición a la teología de la liberación sigue tan pujante (o más) que en los primeros años. Hay, pues, razones serias para sospechar que la manoseada acusación de "ideologla marxista" fue en realidad el disfraz del miedo (a los pobres) que muchos se pusieron, para justificar su empeño por no escuchar una voz que les causaba, y les sigue causando, un profundo malestar. 
Pcro lo del marxismo no fue el único disliraz. Otros han acusado a la teología de la liberación de no ser "cientílica". Es decir, muchos han pensado que no es una teología seria, bien fundamentada. Y lo más que le conceden es que se trata de una denuncia "profética", cargada (en el mejor de los casos) de buena voluntad, pero sin peso especílico en el ámbito propio de la ciencia teológica. Seguramente, esto explica por qué la gran mayoría de los teólogos europeos no ha querido saber gran cosa (y algunos "nada") de la teología de la liberación. Aqui tenemos, según parece, otro disfraz del miedo a los pobres. Un disfraz que, además, obliga a hacerse algunas preguntas. La primera de todas, la más obvia, se refiere al "estatuto epistémico" de la verdad "profética" y de la verdad "cientílica". La pregunta aquí es muy clara: ¿es que la verdad profética puede ser distinta de la verdad cientílica? Dicho de otra manera: ¿es que al profeta le está permitido decir cosas y presentar conclusiones que el hombre de ciencia considera como lalsas o, al menos, como inexactas?

Pero el problema que aquí se plantea cs más de fondo. Si la cosa se piensa despacio, se comprende enseguida que cl discurso profético tiende a presentar la uropia, mientras que el discurso cienlílico tiene como pretensión analizar, desentrañar y presentar la realidad. Es decir, el hombre de ciencia habla de "lo que es", en tanto que el profcta habla de "lo que debería ser". Por eso, el profeta (scgún piensan muchos) suele estar condicionado por la pasión, la subjetividad, quizá fuertes dosis de invecliva y de inventiva, mientras que al hombre de ciencia todo eso le está prohibido. porque su característica es hablar de las cosas "como son". sin carga ideológica alguna y, por tanto, desde la más imparcial objecividad. De ahí que el científico, liberado de subjetividad, de ideología y de pasión, tiene una liabilidad que el prolela no tiene. No sé si cabría decir que el hombre de ciencia está en el centro, si es que se quiere estar en la realidad tal cual es. Mientras que el profela anda por los márgenes, normalmente de la izquierda. Esto es lo que, a grandes rasgos, piensan bastantes "teólogos de raza", por más que no se atrevan a decir lo que realmente piensan de los que, por sus "ideologías" y sus "apasionatnientos", no pasan de ser "hombres de buena voluntad", si es que no son los "tontos útiles" que la izquerda clásica ha utilizado para sus fines turbios.

Ahora bien, a poco que se piense en todo este asunto, enseguida se comprende que, detrás del razonamiento que acabo de hacer, lo que en realidad se esconde es la confronlación de dos formas de pensamiento: la razón analítica (Popper) frente a la razón dialéctica (Adorno, Habermas). Lo que es tanto como decir que aquí nos encontramos con dos lormas de "ideología". Porque pensar, como se ha dicho tantas veces, que el pensamiento científico se caracteriza por carecer de "ideología", eso ya es una "ideología", como tantas veces le han echado en cara a Popper los autores más representativos de la escuela de Franklurt. Y de la misma manera, insinuar que el pensamiento científico está

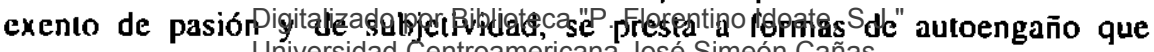
Universidad Centroamericana José Simeón Cañas 
pueden resultar peligrosas. Entre otras razones, porque si imaginamos que el cientílico se calla ciertas cosas porque no pertenecen al ámbito de la ciencia, no convendría olvidar que hay silencios que son más elocuentes que muchos discursos. En este sentido, resulta difícil dejar de pensar que el silencio de tantos tcólogos europeos ante problemas como las agresiones (y la existencia misma) de la OTAN, la "deuda externa" o los abusos brutales del mercado neoliberal, tal silencio es, en realidad, un discurso más elocuente que los análisis más relinados que pueda elaborar la exégesis o la especulación dogmálica.

Para terminar esta cuestión, me parece también peligroso organizar el quehacer intelectual de manera que "las esferas del ser y del deber ser queden separadas" (Habermas). Porque, en ese caso, la ciencia (incluída la ciencia teológica) se niega a considerar como objelo suyo el "ámbito de los valores, normas y decisiones", con lo que se expone a entregar este campo a instancias extracientíficas, o sea, a lo irracional. Y me temo, con bastante fundamento, que no pocas teologías (satisfechas de su rigor científico) andan por ahí. Y es que, a veces, el disfraz del miedo resulta ser un disfraz por el que hay que pagar un precio muy alto. Lo malo es cuando ese precio, en última instancia, tienen que pagarlo quienes tienen menos medios para costear algo tan caro. En cualquier caso, lo que yo tengo más claro es que de "ideologías" y de "pasiones" nadie se escapa. Y. dado que es así, yo prefiero cargar con la ideología y la pasión que, desde mi punto de vista, me parece más coherente a la hora de hacer algo para que este mundo resulte menos inhumano.

Por último, es necesario apuntar (nada más que "apuntar") por dónde va el disfraz eclesiáslico del miedo a los pobres. Cualquiera que conozca la historia de la teología, en los últimos treinta años, sabe de sobra que, en estos años, hablar de Iglesia "popular" o de Iglesia "del pueblo" ha sido y es lo mismo que pronunciar palabras prohibidas. Tan prohibidas que, por evitar todo to que eso llevaba consigo hace pocos años, se ha organizado una enorme "operación eclesial", cuyas consecuencias han sido anular prácticamente a las comunidades eclesiales de base, ncutralizar la libertad de las conferencias episcopales, controlar perfectamente al CELAM, vigilar muy de cerca a la CLAR y, en general, a las religiosas y religiosos. Los efectos de lodo esto están a la vista: Medellín quedó en el recuerdo, los grandes "obispos profetas" de América Latina pasaron a la historia y se alimna con aires de triunfo que la teología de la liberación ha fracasado. El disfraz del miedo ha sido eficaz. Pero no hay que ser un lince para darse cuenta de que ha sido bastante burdo $y$, en cualquier caso, demasiado descarado. 